\title{
PURIFICATION AND CHARACTERIZATION OF A VARIANT OF HUMAN PROTHROMBIN: PROTHROMBIN SEGOVIA
}

\author{
María T. Collados ${ }^{1,3}$, Javier Fernández ${ }^{2}$, José A. Páramo ${ }^{2}$, Ramón Montes ${ }^{1}$, José R. Borbolla ${ }^{2}$, Luis F. \\ Montaño ${ }^{3}$ and Eduardo Rocha ${ }^{2}$ \\ ${ }^{1}$ Laboratory of Vascular Biology and Thrombosis Research, School of Medicine, University of \\ Navarra, Pamplona, ${ }^{2}$ Hematology Service, University Clinic, University of Navarra, Pamplona, Spain \\ and ${ }^{3}$ Department of Cellular Biology, National Institute of Cardiology "Ignacio Chávez", México \\ D.F., México.
}

(Received 9 September 1996 by Editor M. Cattaneo; revised/accepted 24 January 1997)

Abstract: A dysprothrombin designated prothrombin Segovia was isolated from the plasma of an individual with normal prothrombin antigen and prothrombin activity lesser than $25 \%$ of the control prothrombin activity. Activation by prothrombinase complex showed a lower amidolytic than clotting activity, which suggests a lesser generation of active intermediates than normal prothrombin. When prothrombin Segovia was activated by prothrombinase complex in the absence of factor $\mathrm{Va}$, no thrombin formation was found by functional activities. SDS-PAGE analysis of the molecules derived by activation with prothrombinase complex, Taipan snake venom and Echis carinatus venom showed an accumulation of molecules not cleaved at bond Arg320-Ile321. This was more evident with Echis carinatus venom, which only acts on this bond. Our data suggest that the alteration of prothrombin Segovia impairs the scission of bond Arg320-Ile321.

(C) 1997 Elsevier Science Ltd

Dysprothrombinemias represent one of the most uncommon coagulation defects; so far, 21 variants, all of them characterized by a decrease in the functional level of prothrombin compared to the immunologically detectable prothrombin (1), have been reported (2-7).

The conversion of human prothrombin to thrombin requires two cleavages (8): one at bond $\mathrm{A}$ (Arg271-Thr272), that splits prothrombin into fragment $1+2(\mathrm{~F} 1+2)$ and prethrombin $2(\mathrm{P} 2)$, and another at bond B (Arg320-Ile321), which exposes the active site (9) and yields the disulfide-linked two-chain ( $A$ and $B$ chains) enzyme thrombin. These cleavages can be produced in the opposite order, yielding first the disulfide-linked two-chain active intermediate meizothrombin (MT), and then, thrombin. There are also two more peptide bonds susceptible to autocatalysis; bond C (Arg155Ser156), and bond D, (Arg286-Thr287). Cleavage of bond C from prothrombin produces prethrombin

Key words: dysprothrombinemia, prothrombin activation, prothrombinase complex.

Corresponding author: Dr. María T. Collados, Department of Cellular Biology, Instituto Nacional de Cardiología. Tezoquipa 101-107, Col. La Joya, C.P.,14090. México D.F., México. Fax:52-5-6552033 
1 (P1), and from MT produces meizothrombin-desF1 (MT-desF1), another disulfide linked two chain active intermediate $(10,11)$.

Eleven of the prothrombin variants have been purified and characterized $(2,12)$. Prothrombins Barcelona and Madrid, have a functional defect affecting bond $\mathrm{A}$; prothrombin Clamart has a functional defect affecting bond B; prothrombin San Juan is thought to have a calcium binding defect, and finally, an abnormality of the thrombin active site has been demostrated for prothrombins Molise, Quick, Metz, Salakta, Tokushima, Habana and Himi $(2,7,13,14)$.

The specific molecular defect has been identified as a single amino-acid substitution in the dysprothrombinemias Barcelona and Madrid (Arg271 $\rightarrow$ Cys) $(15,16)$, Tokushima (Arg418 $\rightarrow$ Trp) (17, 18) and Salakta (Glu466 $\rightarrow$ Ala) (19) and as a double amino-acid substitution in protrombins Quick (Arg382 $\rightarrow$ Cys and Gly588 $\rightarrow$ Val) $(20,21)$ and Himi (Met337 $\rightarrow$ Thr and Arg388 $\rightarrow$ His) (22), which are the two unique cases known to be compounds heterozygous for two dysfunctional prothrombin molecules.

Prothrombin Segovia (1), characterized by abnormally low levels of plasma prothrombin activity using both physiologic activators as well as Russell, Notechis scutatus or Echis carinatus venoms, showed a more cathodic mobility in plasma immunoelectrophoresis than normal prothrombin, and had in the bidimensional electrophoresis of the propositu's serum three peaks instead of the normal two. These data suggested that prothrombin Segovia was a new dysfunctional prothrombin molecule. Therefore, the aim of this work was its purification and functional characterization.

\section{MATERIAL AND METHODS}

Blood was collected from the proband using plastic syringes that contained 1/10 (v:v) of $3.8 \%$ trisodium citrate. Platelet-poor plasma was obtained after centrifugation at $2500 \mathrm{~g}$ for 30 minutes at $4^{\circ} \mathrm{C}$ and stored $\mathrm{a}-80^{\circ} \mathrm{C}$.

Prothrombin obtained from the already refered (1) heterozygous patient and named, for the remaining of this manuscript, as prothrombin Segovia, was isolated by barium citrate adsortion/elution, ammonium sulphate precipitation (23) and DEAE Sephadex (Pharmacia) chromatography (24). It was then studied by immunoelectrophoresis performed according to Scheidgger et al (25), bidimensional electrophoresis carried out according to a modification (26) of the Clarke and Freeman method (27), and SDS-PAGE according to Weber and Osborn (28).

\section{Prothrombin activation:}

Experiments with prothrombin Segovia were done in parallel with control prothrombin, using purified bovine factors $\mathrm{Xa}$ and $\mathrm{V}$ (Diagen), rabbit brain cephaline (Sigma), Echis carinatus and Oxyuranus scutellatus (Taipan snake) venoms (Sigma).

Thrombin clotting activity was determined by its ability to clot human purified fibrinogen (KabiVitrum), using human thrombin (Roche) for the calibration curve. Amidolytic activity of thrombin and thrombin-like enzymes was determined by following spectrophotometrically the hydrolysis of the chromogenic substrate S-2238 (H-D-Phe-Pip-Arg-pNA) (Kabi-Vitrum) at 405 (29).

Prothrombin activation products were identified by SDS-PAGE with and without dithiothreithol (DTT), in order to identify the following molecules: prothrombin and MT (72000), P1 and MT-desF1 
(57000) and $P 2$ and thrombin (38000). When Echis carinatus venom was used as activator, prothrombin activation products were analyzed by Western blot $(30,31)$. Determination of $F 1+2$ was performed according to the method of Pelzer (32) using a commercially available immunoassay (Behring).

The incubation mixtures were the following:

a. Prothrombinase complex: prothrombin $(4.2-8.4 \mu \mathrm{g} / \mathrm{ml})$ was incubated with factor $\mathrm{Xa}(0.02 \mathrm{U} / \mathrm{ml})$, factor $\mathrm{V}(0.012 \mathrm{U} / \mathrm{ml})$ and rabbit brain cephalin $(1: 5 \mathrm{v} / \mathrm{v})$ in $0.1 \mathrm{M}$ Tris, $0.1 \mathrm{M} \mathrm{NaCl}, 0.01 \mathrm{M} \mathrm{CaCl}_{2}$, $\mathrm{pH}=7.4$. In absence of factor $\mathrm{V}$, the concentration of factor $\mathrm{Xa}$ was $2 \mathrm{U} / \mathrm{ml}$. In SDS-PAGE and F1+2 determination, prothrombin $(25 \mu \mathrm{g} / \mathrm{ml})$ was incubated with factor $\mathrm{Xa}(0.35 \mathrm{U} / \mathrm{ml})$, factor $\mathrm{V}(0.024$ $\mathrm{U} / \mathrm{ml}$ ) and rabbit brain cephalin (1:3.5 v/v) in $0.1 \mathrm{M}$ Tris, $0.1 \mathrm{M} \mathrm{NaCl}, 0.04 \mathrm{M} \mathrm{CaCl}_{2}, \mathrm{pH}=7.4$.

b. Taipan snake venom: prothrombin $(2.1-4.2 \mu \mathrm{g} / \mathrm{ml})$ was incubated with the venom $(0.2 \mu \mathrm{g} / \mathrm{ml})$ and rabbit brain cephalin $(1: 10 \mathrm{v} / \mathrm{v})$ in $0.05 \mathrm{M}$ Tris, $0.1 \mathrm{M} \mathrm{NaCl}, 0.01 \mathrm{M} \mathrm{CaCl}_{2}, \mathrm{pH}=7.4$. In SDS-PAGE and $\mathrm{Fl}+2$ determination, prothrombin $(50 \mu \mathrm{g} / \mathrm{ml})$ was incubated with the venom $(16 \mu \mathrm{g} / \mathrm{ml})$ and rabbit brain cephalin $(1: 9 \mathrm{v} / \mathrm{v})$ in $0.05 \mathrm{M}$ Tris, $0.1 \mathrm{M} \mathrm{NaCl}, 0.04 \mathrm{M} \mathrm{CaCl}_{2}, \mathrm{pH}=7.4$.

c. Echis carinatus venom: prothrombin $(4.2-8.4 \mu \mathrm{g} / \mathrm{ml})$ was incubated with the venom $(2.5 \mu \mathrm{g} / \mathrm{ml})$ in $0.02 \mathrm{M}$ Tris, $0.1 \mathrm{M} \mathrm{NaCl}, \mathrm{pH}=7.4$. In SDS-PAGE and F1+2 determination, prothrombin $(60 \mu \mathrm{g} / \mathrm{ml})$ was incubated with the venom $(35 \mu \mathrm{g} / \mathrm{ml})$ in the above buffer.

\section{RESULTS}

After the adsorption of propositu's plasma onto barium citrate and the elimination of most plasma proteins, two peaks were obtained from the DEAE-Sephadex column. The second of them containing prothrombin Segovia, similary to normal prothrombin, eluted at the same ionic strength, migrated as a single band, had the same mobility in SDS-PAGE and its molecular weight was estimated as 72000 (fig. 1). Nevertheless, the immunoelectrophoretic mobility of this prothrombin was more cathodic than that of normal prothrombin, already confirmed by bidimensional electrophoresis.

Activation of the propositu's purified prothrombin, (prothrombin Segovia), by the prothrombinase complex showed a delay of thrombin production, determined by clotting as well as amidolytic activity (fig. 2). The thrombin activity generated by prothrombin Segovia was $85 \%$ of the normal activity upon fibrinogen and $35 \%$ upon synthetic substrate S-2238. However, similary to normal prothrombin, prothrombin Segovia reached maximum amidolytic activity faster than maximum clotting activity. When the activation was carried out in absence of factor $\mathrm{Va}$, no clotting activity appeared from prothrombin Segovia and amidolytic activity reached a plateau at less than $5 \%$ of the normal maximum activity (fig. 2). The rate of $\mathrm{F} 1+2$ production by prothrombin Segovia was similar to that of normal prothrombin (fig. 3a). Although the cleavage pattern of both prothrombins on SDS-PAGE was similar, the appearance of 57,000 (P1 or MT-desF-1) and $38,000 \mathrm{Da}$ (P2 or thrombin) fragments occurred later in prothrombin Segovia. DTT reduction had a more intensive effect on the activation of normal prothrombin fragments producing B chain, while on prothrombin Segovia, only a decrease of intensity of the fragments was seen (data non shown).

After activation with Taipan snake venom, Segovia' and normal prothrombins reached clotting and amidolytic activity plateaus at the same time (45 and 20 minutes respectively) (fig. 4) but the former generated $36 \%$ and $42.8 \%$ of clotting and amidolytic activity in relation to the latter. $\mathrm{F} 1+2$ production was similar to that of normal prothrombin, and greater than with the rest of activators (fig. $3 b$ ). 
Cleavage pattern by SDS-PAGE showed a delay in prothrombin Segovia activation and an accumulation of prothrombin, $\mathrm{P1}$ and $\mathrm{P} 2$ non susceptible to reduction.

Activation of prothrombin Segovia with Echis carinatus venom was very impaired. As shown in fig. 4, the production of thrombin from prothrombin Segovia, measured by clotting as well as amidolytic activity, was less than $5 \%$ of the produced by normal prothrombin, even after one hour incubation. $\mathrm{F} 1+2$ concentration was one-fifth that generated in normal prothrombin (fig. $3 \mathrm{c}$ ). Very slow activation of prothrombin Segovia was observed in SDS-PAGE, because while the formation of thrombin was clearly appreciated in normal prothrombin, it was not observed in prothrombin Segovia. After reduction, the intermediate fragments of normal prothrombin activation produced $B$ chain, while in prothrombin Segovia there was a decrease in the intensity of transitory products, without B chain formation (fig. 5). Nevertheless, the cleavage pattern of prothrombin Segovia activation studied by Western blot, showed minute thrombin formation in the last periods of incubation (fig. 6).

\section{DISCUSSION}

The fact that there is less amidolytic than clotting activity in prothrombin Segovia after activation with prothrombinase complex, suggests that the molecule generates less active intermediates than normal prothrombin. This can be explained because while the action on substrate S-2238 is produced by active intermediates (MT and MT-desF1) (33) as well as thrombin, the clotting activity is only generated by thrombin (13). Moreover, the great resistance of prothrombin Segovia to reduction of intermediates, points to an accumulation of intermediates lacking a cleaved bond B (Arg320-Ile321), and therefore, not expressing the active site. However, the clotting activity and the formation of the $57000 \mathrm{Da}$ intermediate, which is a product of autolysis (34), shows thrombin formation, although in a lesser degree than in normal prothrombin.

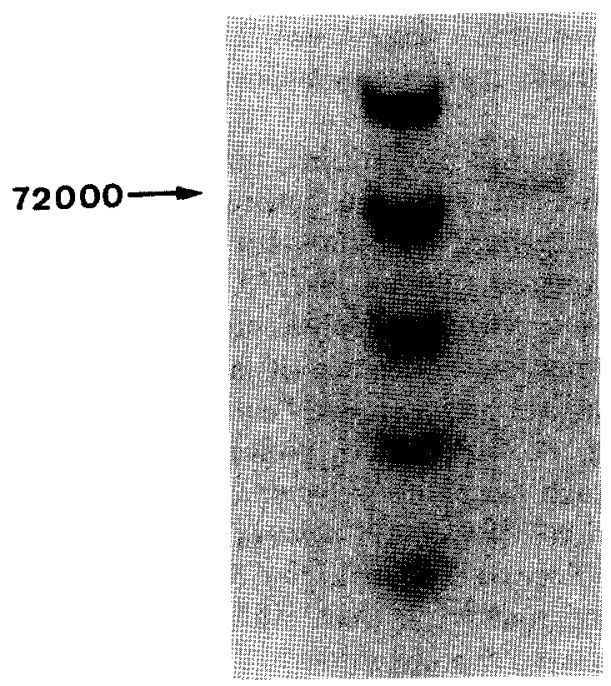

FIG. 1

Polyacrilamide gel electrophoresis in the presence of sodium dodecyl sulfate (SDS-PAGE) of purified and prothrombin Segovia. 

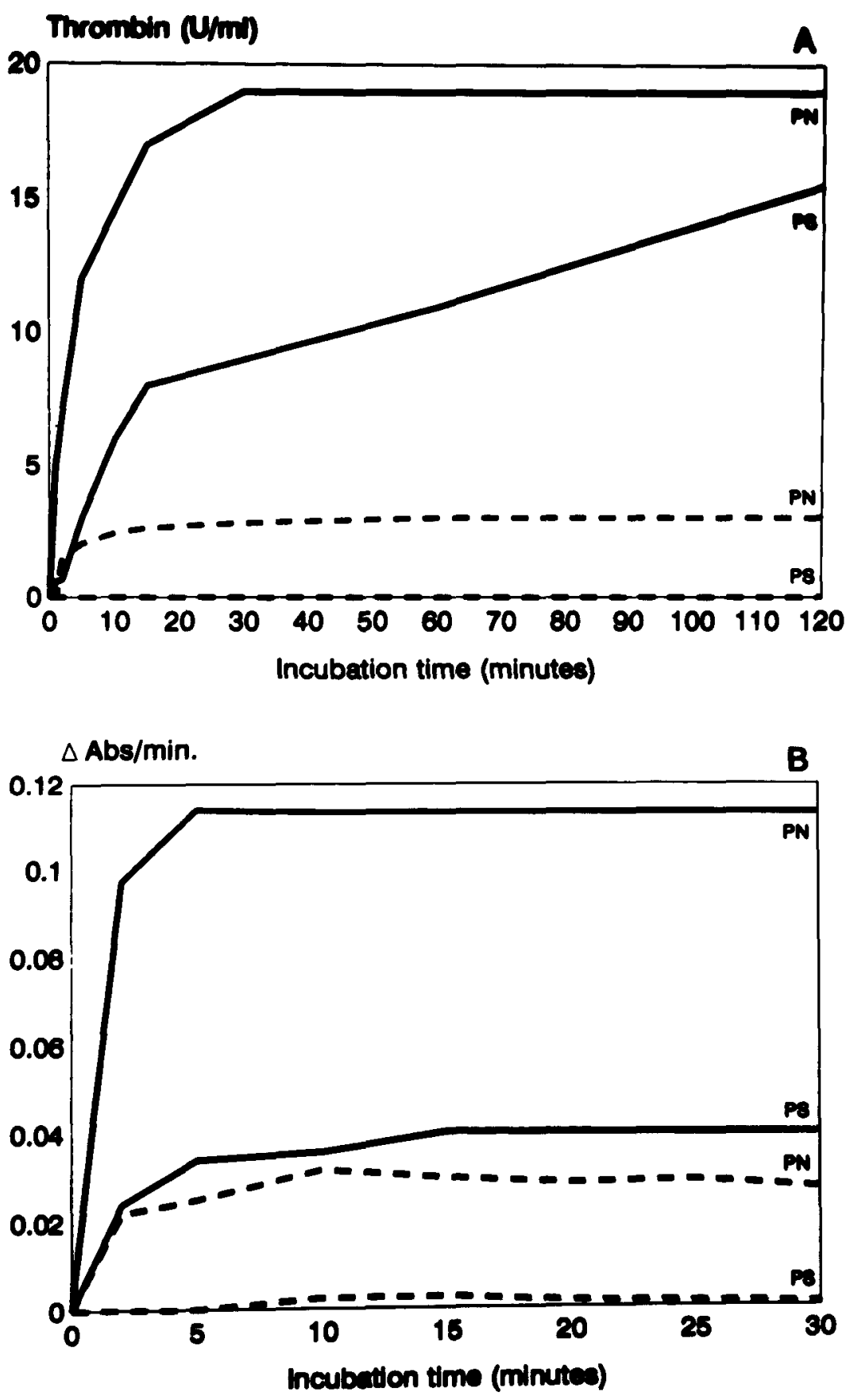

FIG. 2

Activities generated during activation of prothrombin Segovia (PS) and normal prothrombin (PN) by prothrombinase complex in the presence (black line) and absence (striped line) of factor V. A) Clotting activity; B) amidolytic activity. 

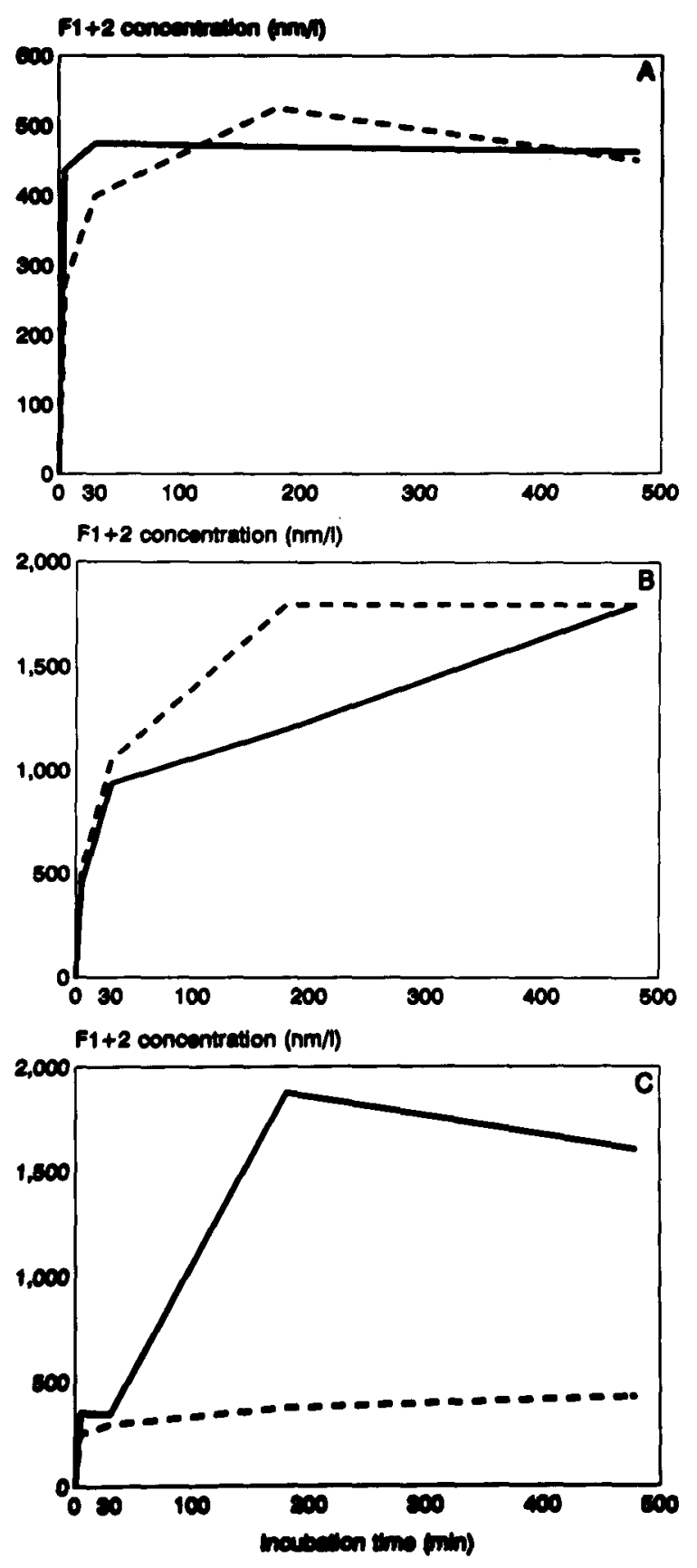

FIG. 3

Fragment $F 1+2$ concentration generated during activation of prothrombin Segovia (striped line) and normal prothrombin (black line) by: A) prothrombinase complex; B) Taipan snake venom and C) Echis carinatus venom. 

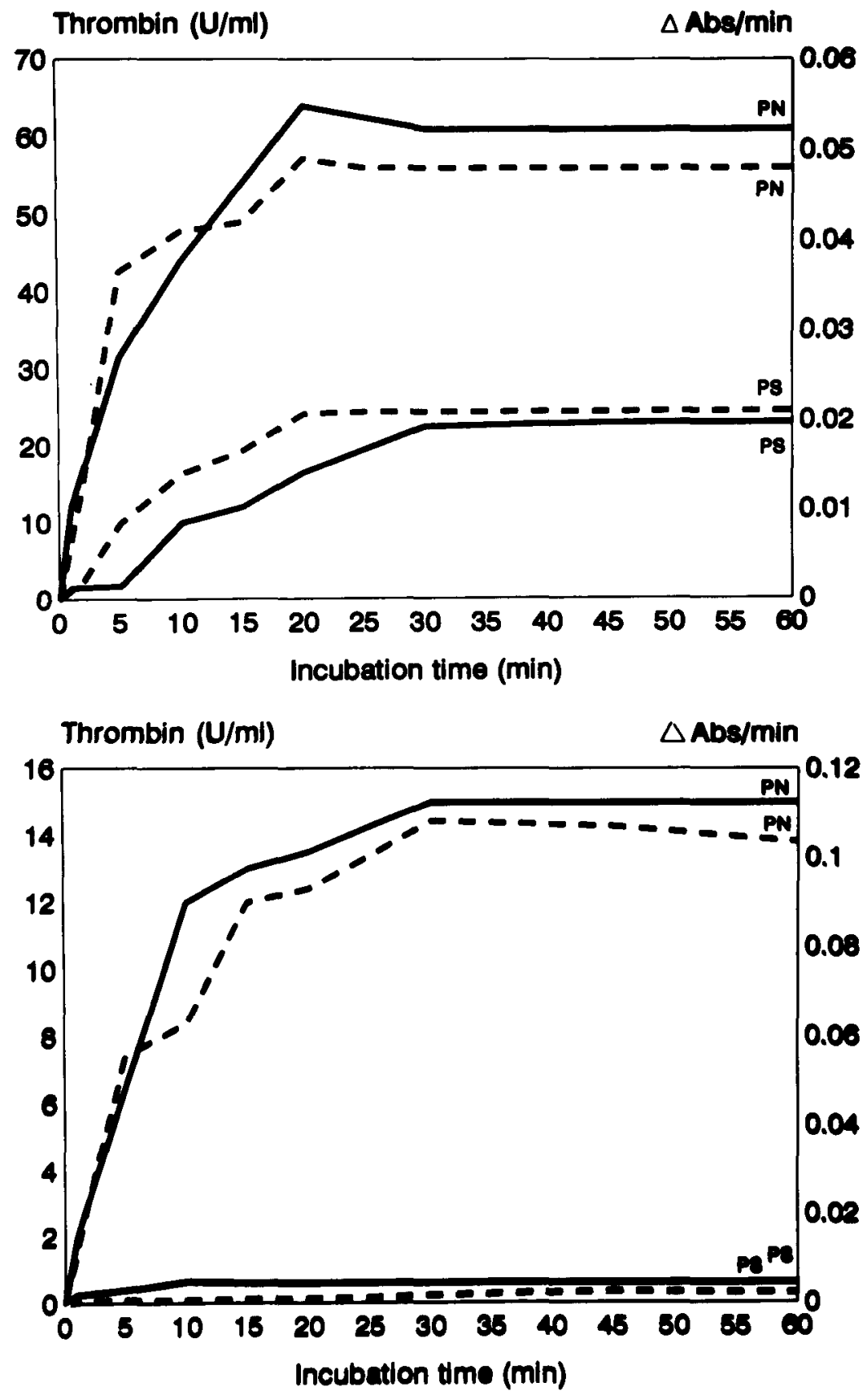

FIG. 4

Activities generated during activation of prothrombin Segovia (PS) and normal prothrombin (PN) by Taipan snake venom (top) and Echis carinatus venom (bottom). Clotting activity in black line and amidolytic activity in striped lime. 
Upon activation by Taipan snake venom, prothrombin Segovia reached a plateau of clotting and amidolytic activities at the same time, thus demonstrating that thrombin is the only active enzyme (35) and that the activation pathway is through P2 (36). Similar to prothrombinase complex, resistence to reduction is reflected by the accumulation of $\mathrm{P} 2$. Nevertheless, the clotting activity and the production of the $57000 \mathrm{Da}$ intermediate, result of autolysis, points out to a small thrombin production.

The dramatically decrease thrombin formation from prothrombin Segovia with Echis carinatus venom suggests an impairement of proteolysis at bond B, because this venom cleaves only the single Arg320Ile321 bond forming meizothrombin, with the rest of reactions being autocatalytic $(37,38)$. However
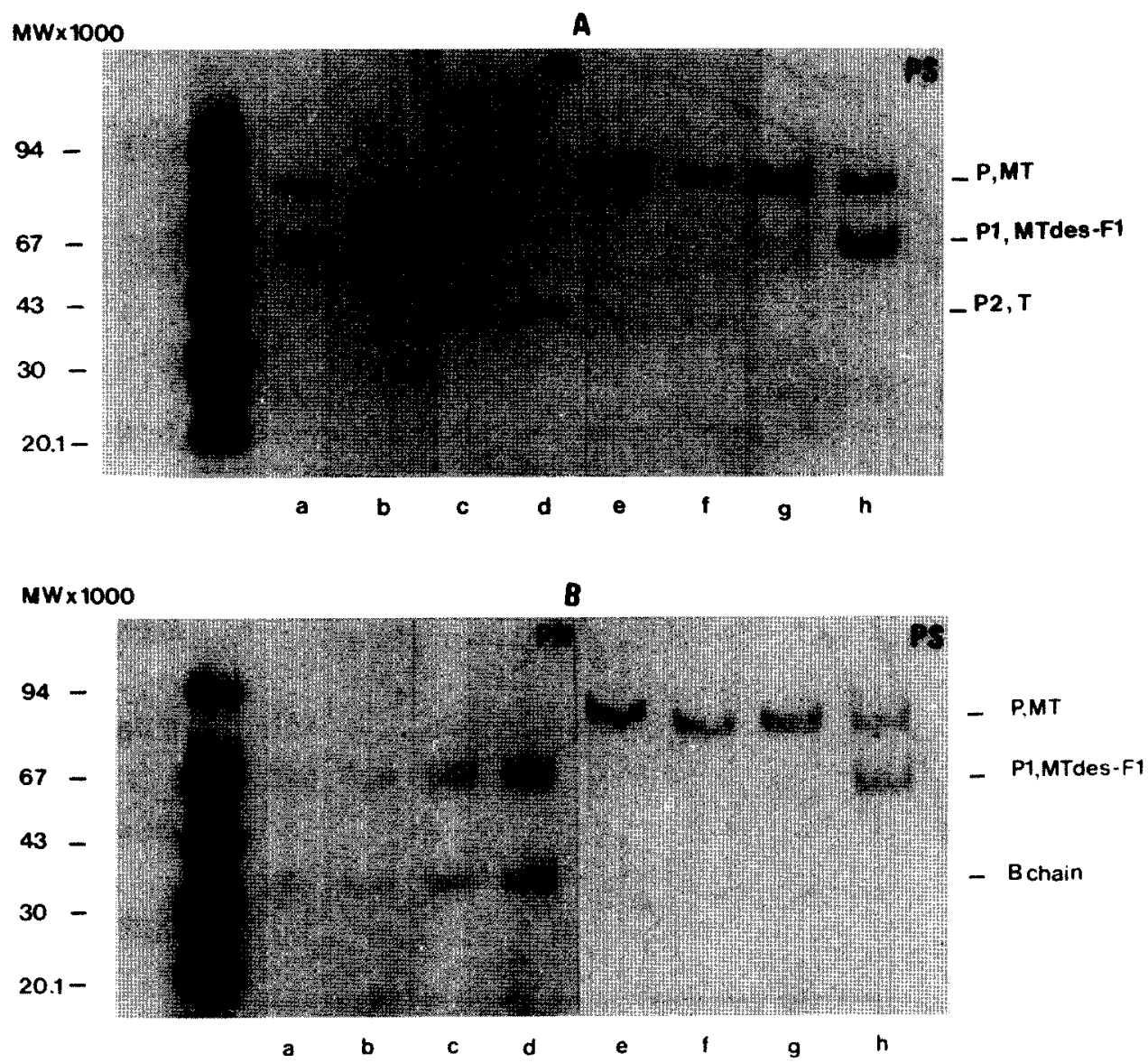

FIG. 5

Cleavage patterns of normal prothrombin (PN) and prothrombin Segovia (PS) by Echis carinatus venom under $\mathrm{A}$ ) non reduced and $\mathrm{B}$ ) reduced conditions. Lanes a to $\mathrm{d}$ in $\mathrm{PN}$ and lanes $\mathrm{e}$ to $\mathrm{h}$ in PS: time 5, 30, 480 minutes and 24 hours. P, prothrombin; MT, meizothrombin; P1, prethrombin-1; MT-desF1, meizothrombin-desF1; P2, prethrombin 2; T, thrombin. 


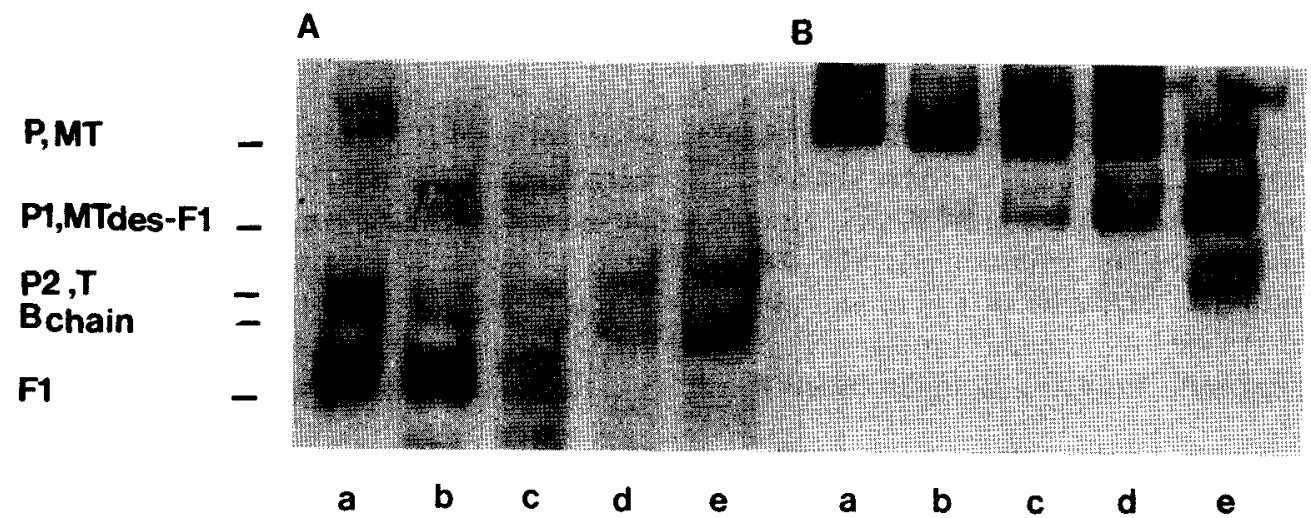

FIG 6

Western blot under reduced conditions of cleavage patterns of A) normal and B) prothrombin Segovia by Echis carinatus venom Lanes a to e: time 5, 30, 180, 480 minutes and 24 hours. P, prothrombin; MT, meizothrombin; P1, prethrombin 1; MT-desF1, meizothrombin-desF1; $\mathrm{P} 2$, prethrombin 2; T, thrombin; F1, fragment 1.

SDS-PAGE analysis insinuated some degree of activation, shown by the parallelism between the increase in the $57000 \mathrm{Da}$ intermediate intensity and the decrease in the $72000 \mathrm{Da}$ intermediate intensity, which suggests that the former is formed from the latter. This activation was also confirmed by the appearance of thrombin in the Western blot, and by the generation of F1+2.

Up until now, the known dysprothrombinemias have been characterized by defects in the following sites: a) scission of bond $A ; b$ ) fragment 1 ; c) thrombin part of the molecule (dysthrombinemia); and d) scission of bond $\mathrm{B}$. The formation of $\mathrm{P} 2$, thrombin and $\mathrm{F} 1+2$ with prothrombinase complex and Taipan snake venom, suggests that scission of bond A, Arg271-Thr272 in prothrombin Segovia is normal. Moreover, in prothrombins Barcelona (39) and Madrid (40), which are characterized by this defect, the activation with Echis carinatus venom was normal, in contrast to prothrombin Segovia. We can also discard an abnormality in fragment F1 like that of prothrombin San Juan (41), because prothrombin Segovia is quantitatively adsorved in barium salt and its immunoelectrophoretic pattern in the presence of calcium is normal.

There are some similarities between prothrombin Segovia and some well recognized dysthrombinemias, i.e., a decrease of clotting and amidolytic activities after activation with prothrombinase complex, similar to prothrombins Molise (42), Quick (43), Metz (44), Tokushima (45), Salakta (46), Habana (14) and Himi (7). However, in these dysthrombinemias, the decrease with prothrombinase complex and Taipan snake venom was more drastic that in prothrombin Segovia. On the other hand, the behaviour of intermediates of prothrombin Segovia after reduction was different than that found in dysthrombinemias where B chain was produced. In prothrombin Himi (7), after activation with Echis carinatus venom, the cleavage pattern was normal, which is very different to prothrombin Segovia. We can not discard a defect in the thrombin part of prothrombin Segovia; such a defect, would explain the delay in its activation with prothrombinase complex and Echis carinatus venom. 
An alteration in the scission of bond B, was first postulated by Rocha et al (1986) who found a distinctive pattern of peaks in bidimensional eletrophoresis (1), generally related with a defect in the activation process $(2,12)$.

The only dysprothrombinemia where an altered cleavage of bond $\mathrm{B}$, probably induced by an affinity impairement of factor $\mathrm{Xa}$ to prothrombin (47), has been found, is prothrombin Clamart which has the following characteristics: the thrombin generation rate by prothrombinase complex is twice as slow as that of normal prothrombin and SDS-PAGE analysis of the final activation products reveals an abnormal accumulation of $\mathrm{P} 2$, resistant to reduction, with a lesser degree of thrombin formation. Similar results were found in prothrombin Segovia with the prothrombinase complex and the Taipan snake venom. The defect in prothrombin Clamart lies in the scission of bond B, Arg320-Ile321.

The lesser degree of amidotytic than clotting activity observed in prothrombin Segovia and the accumulation of Arg320-Ile321 intermediates not cleaved with the prothrombinase complex, suggest fewer intermediates with an uncovered active site. The more evident result was produced with Echis carinatus venom, which acts solely on bond $B(48)$, because when it was used as activator, thrombin formation was practically absent and after the reduction of activation intermediates, the $B$ chain did not appear in the SDS-PAGE analysis. Nevertheless, the production of clotting and amidolytic activities as well as autolysis reactions (49), suggests a small cleavage of this bond.

In order to study factor Va influence, prothrombin Segovia was activated with prothrombinase complex in the absence of factor $\mathrm{V}$. Very poor or no thrombin generation was found by amidolytic activity or by clotting activity, respectively. Several studies have shown that factor Va not only binds to the substrate, prothrombin, but also modulates the conformation of its protease domain, determining the proteolysis efficiency of factor $\mathrm{Xa}(50,51,52,53)$. Since factor Va produced a moderately active thrombin molecule from prothrombin Segovia, it is possible that factor Va made the scission of bond B easier, probably by inducing a more appropiate conformation of prothrombin.

Our results suggest that the defect of prothrombin Segovia impairs the correct scission of bond B, Arg320-Ile321, although it is unlikely that it is located in one of these amino-acids.

\section{REFERENCES}

1. ROCHA, E., PARAMO, J.A., BASCONES, C., FISAC, P.R., CUESTA, B. and FERNANDEZ, J. Prothrombin Segovia: a new congenital abnormality of prothrombin. Scand J Haematol 36, 444-449, 1986.

2. ROCHA, E., FERNANDEZ, F.J., CUESTA, B., PARAMO, J.A. and RIFON, J. Anomalías moleculares congénitas del fibrinógeno y de la protrombina. Sangre 34, 210-220, 1989.

3. DUMONT, M.D., TAPON-BRETAUDIERE, J., FISHER, A.M., BROS, A., CHASSEVENT, J. and AUFEVRE, J.P. Prothrombin Poissy: a new variant of human prothrombin. Br J Haematol 66, 239-243, 1987.

4. LUTZE, G., FRICK, U., TOPFER, G. and URBAHN, H. Hereditaine dysprothrombinamie mit geringer Blutungsneigung (Prothrombin Madgeburg). Dtsch Med Wochenschr 114, 288-292, 1989.

5. VALLS DE RUIZ, M., RUIZ ARGÛELLES, A., RUIZ ARGÛELLES, G.J. and AMBRIZ, R. Prothrombin "Mexico-city", an asymptomatic autosomal prothrombin variant. Am J Haematol 24, 229$240,1987$.

6. RABIET, M.J., FURIE, B.C. and FURIE, B. Molecular defect of prothrombima Barcelona. Substitution of Cys for Arg at residue 273. J Biol Chem 261, 15045-15048, 1986. 
7. MORISHITA, E., SAITO, M., ASAKURA, H., JOKAJ, H., UOTANI, C., KUMABASHIRI, I., YAMAZAKI, M., HACHIYA, H., OKAMURA, M. and MATSUDA, T. Prothrombin Himi: an abnormal prothrombin characterized by a defective thrombin activity. Thromb Res 62, 697 $706,1991$.

8. JACKSON, C.M. Mechanism of prothrombin activation. In: Hemostasis and Thrombosis: Basic Principles and Clinical Practice. R.W. Colman, J. Hirsh, V.J. Marder and E.W. Salzman (Eds.), pp. 100-111, J.B.Lippincott Company, Philadelphia (1982).

9. MANN, K.G. and LUNDBLAD, R. Biochemistry of thrombin. In: Hemostasis and Thrombosis: Basic Principles and Clinical Practice. R.W. Colman, J. Hirsh, V.J. Marder jand E.W. Salzman (Eds.), pp. 112-126, J.B.Lippincott Company, Philadelphia (1982).

10. NESHEIM, M.E., ABBOTT, T., JENNY, R. and MANN, K.G. Evidence that the thrombincatalyzed feedback cleavage of fragment 1,2 at Arg-Ser promotes the release of thrombin from the catalytic surface during the activation of bovine prothrombin. J Biol Chem 263, 1037-1044, 1988.

11. RABIET, M.J., BLASHILL, A., FURIE, B. and FURIE, B.C. Protrhombin fragment 1,2,3, a major product of prothrombin activation in human plasma. J Biol Chem 261, 13210-13215, 1986.

12. GUILLIN, M.C., BEZEAUD, A., RABIET, M.J. and ELION, J. Congenitally abnormal prothrombin and thrombin. Ann NY Acad Sci 1, 56-65, 1986.

13. KRISHNASWAMY, S., MANN, K.G. and NESHEIM, M.E. The prothrombinase-catalyzed activation of prothrombin proceeds through the meizothrombin in an ordered sequential reaction. J Biol Chem 261, 8977-8984, 1986.

14. DIAZ, A., RUBIO, R. and BIGGS, R. Purificación y caracterización parcial de la protrombina Habana. Rev Iberoam Tromb Hemostasia 3, 106-109, 1990.

15. RABIET, M.J., FURIE, B.C. and FURIE, B. Molecular defect of prothrombina Barcelona. Substitution of Cys for Arg at residue 273. J Biol Chem 261, 15045-15048, 1986.

16. DIUGUID, D.L., RABIET, M.J., FURIE, B.C. and FURIE B. Molecular defect of factor IX Chicago-2 and prothrombin Madrid (Arg 271-Cys): Arg mutations that preclude zymogen activation. Blood 74, 193-200, 1989.

17. MIYATA, T., MORITA, T., INOMOTO, T., KAWAUCHI, S., SHIRAKAMI, A. and IWANAGA, S. Prothrombin Tokushima: a replacement of Arg 418 by Trp that impairs fibrinogen clotting activity of derived thrombin Tokushima. Thromb Haemostasis 98, 312, 1987.

18. IWAHANA, H., YOSHIMOTO, K., SHIGEKIYO, T., SHIRAKAMI, A., SAITO, S. and ITAKURA, M. Detection of a single base substitution of the gene for thrombin Tokushima. The application of PCR-SSCP for the genetic and molecular analysis of dysprothrombinemia. Int $J$ Hematol 55, 93-100, 1992.

19. MIYATA, T., ARUGA, R., UMEYAMA, H., BEZEAUD, A., GUILLIN, M.C. and IWANAGA, S. Thrombin Salakta: substitution of glutamic acid-466 by alanine reduces the fibrinogen clotting activity and the esterase activity. Biochemistry 31, 7457-7462, 1992.

20. HENRIKSEN, R.A. and MANN, K.G. Identification of the primary structural defect in thedysthrombin thrombin Quick I: substitution of cysteine for arginine-382. Biochemistry 27, 9160-9165, 1988.

21. HENRIKSEN, and MANN, K.G. Substitution of valine for glycine-558 in the congenital dysthrombin thrombin Quick II alters primary substrate specificity. Biochemistry 28, 2078-2082, 1989.

22. MORISHITA, E., SAITO, M., KUMABASHIRI, I., ASAKURA, H., MATSUDA, T. and YAMAGUCHI, K. Prothrombin Himi: a compound heterozygote for two dysfunctional prothrombin molecules (Met337 $\rightarrow$ Thr and Arg388 $\rightarrow$ His). Blood 80, 2275-2280, 1992. 
23. SHAPIRO, S.S. and WAUGH, D.F. The purification fo human prothrombin. Thromb Diath Haemorrh 16, 469-490, 1966

24. MORRISSON, S.A. and ESNOUF, M.P. The nature of the heterogeneity of prothrombin during dicoumarol therapy. Nature New Biol 242, 92-94, 1973.

25. SCHEIDGGER, J.J. Une micro-method the l'immunoelectrophoresis. Int Arch Allergy 7, $103-$ $110,1955$.

26. FERNANDEZ, J., ANGULO, P., SAN MARTIN, B. and GOÑI, M. Electroforesis bidimensional II. Métodos de identificación de inmunoprecipitados (gel intermedio y electroforesis tándem). Rev Diag Biol 27, 23-27, 1978.

27. CLARKE, H.G.M. and FREEMAN, T. A quantitative immunoelectrophoresis of human serum proteins. Clin Sci 35, 403-413, 1968.

28. WEBER, K. and OSBORN, M. The realibility of molecular weight determination by dodecyl sulphate polyacrilamide gel electrophoresis. J Biol Chem 244, 4406-4412, 1969.

29. LOTTENBERG, R., HALL, J.A., BLINDER, M., BINDER, E.O. and JACKSON, C.M. The action of thrombin on peptide p-nitroanilide substrates. Biochim Biophys Acta 742, 539-557, 1983.

30. GERSHONI, J.M. and PALADE, G.E. Review. Protein blotting principles and applications. Anal Biochem 13I, 1-15, 1983.

31. HEEGAARD, N.H.H. and BJERRUM, O.J. Immunoblotting. General principles and procedures. In: CRC handbook of immunoblotting of proteins. O.J. Bjerrum and N.H.H. Heegaard (Eds.), pp. 1-25, CRC Press, Florida (1988).

32. PELZER, H., SCHWARZ, A. and STUBER, W. Determination of human prothrombin activation fragment $1+2$ in plasma with an antibody against a synthetic peptide. Thromb Haemostasis 65, 153-159, 1991.

33. ROSING, J., ZWAAL, R.F.A. and TANS, G. Formation of meizothrombin as intermediate in factor Xa-catalyzed prothrombin activation. J Biol Chem 261, 4224-4228, 1986.

34. ROSENBERG, J.S., BEELER, D.L. and ROSENBERG, R.D. Activation of human prothrombin by highly purified human factors $\mathrm{V}$ and $\mathrm{Xa}$ in presence of human antithrombin III. $\mathrm{J}$ Biol Chem 250, 1607-1617, 1975.

35. JACKSON, C.M. The biochemistry of prothrombin activation. In: Haemostasis and Thrombosis. A.L. Bloom and D.P. Thomas (Eds), pp. 165-191, Churchill Livingstone, New York (1987).

36. OWEN, W.G. and JACKSON, C.M. Activation of prothrombin with Oxyuranus scutellatus scutellatus (Taipan snake) venom. Thromb Res 3, 705-714, 1973.

37. RHEE, M.J., MORRIS, S. and KOSOW, D.P. Role of meizothrombin and meizothrombin(des F1) in the conversion of prothrombin to thrombin by Echis carinatus venom. Biochemistry $21,3437-3443,1982$.

38. BRIET, M.J., NOYES, C.M., ROBERTS, H.R. and GRIFFITH, M.J. Cleavage and activation of human prothrombin by Echis carinatus venom. Thromb Res 27, 591-600, 1982.

39. RABIET, M.J., ELION, J., BENAROUS, R., LABIE, D. and JOSSO, F. Activation of prothrombin Barcelona. Biochim Biophys Acta 584, 66-75, 1979.

40. GUILLIN, M.C. and BEZEAUD, A. Characterization of a variant of human prothrombin: prothrombin Madrid. Ann NY Acad Sci 370, 414-425, 1981.

41. SHAPIRO, S.S., MALDONADO, N.I., FRADERA, J. and McCORD, S. Prothrombin San Juan: a complex new dysprothrombinemia. J Clin Invest 53, 73A, 1974.

42. RABIET, M.J. Prothrombin Molise: a mutant prothrombin characterized by a defect in the thrombin domain. Thromb Haemostasis 54, 46, 1985. 
43. OWEN, C.A., HENRICKSEN, R.A., FREDERIC, C., McDUFFIE, M.D. and MANN, K.G. Prothrombin Quick: a newly identified dysprothrombinemia. Mayo Clinic Proc 53, 29-33, 1978. 44. RABIET, M.J., JANDROT-PERRUS, M., BOISSEL, J.P. and JOSSO, F. Thrombin Metz: characterization of the dysfunctional thrombin derived from a variant of human prothrombin. Blood 63, 927-934, 1984

45. INOMOTO, T., SHIKARAMI, A., KAWAUCHI, S., SHIGEKIYO, T., SAITO, S., MIYOSHI, K., MORITA, T. and IWANAGA, S. Prothrombin Tokushima:characterization of dysfunctional thrombin derived from a variant of human prothrombin. Blood 69, 565-569, 1987.

46. BEZEAUD, A., DROUET, L., SORIA, C.C. and GUILLIN, M.C. Prothrombin Salakta: an abnormal prothrombin characterized by a defect in the active site of thrombin. Thromb Res 34 , 507-518, 1984.

47. HUISSE, M.G., DREYFUS, M. and GUILLIN, M.C. Prothrombin Clamart:prothrombin variant with defective Arg320-Ile cleavage by factor Xa. Thromb Res 44, 11-21, 1986.

48. MORITA, T. and IWANAGA, S. Prothrombin activator from Echis carinatus venom. Methods Enzymol 80, 303-311, 1981.

49. TIJBURG, P.N.M., VAN HEERDE, W.L., LEENHOUTS, H.M., HESSING, M., OUMA, B.N. and DE GROOT, P.G. Formation of meizothrombin as intermediate in factor Xa-catalyzed prothrombin activation on endothelial cells. The influence of thrombin on the reaction mechanism. J Biol Chem 266, 4017-4022, 1991.

50. ARMSTRONG, S.A., HUSTEN, E.J., ESMON, C.T. and JOHNSON, A.E. The active site of membrane-bound meizothrombin. A fluorescence determinaation of its distance from the phospholipid surface and its conformational sensitivity to calcium and factor Va. J Biol Chem $265,6210-6218,1990$.

51. HUSTEN, E.J., ESMON, C.T. and JOHNSON, A.E. The active site of blood coagulation factor Xa. Its distance from the phospholipid surface and its conformational sensitivity to components of the prothrombinase complex. J Biol Chem 262, 12953-12962, 1987.

52. CARLISLE, T.L., BOCK, P.E. and JACKSON, C.M. Kinetic intermediates in prothrombin activation. J Biol Chem 265, 22144-22155, 1990.

53. JACKSON, C.M. and NEMERSON, Y. Blood coagulation. Annu Rev Biochem 49, 765-811, 1980. 